\title{
RELAÇÕES DE PODER NO EXAME CELPE-BRAS
}

\author{
POWER RELATIONS IN CELPE-BRAS EXAM
}

\author{
Ana Maria $\mathcal{N}$ Cápoles Villela*, Liliane de Oliveira $\mathcal{N}_{\text {Ceves** }}^{* *}$ \\ e Natália Moreira Tosatti****
}

Centro Federal de Educação Tecnológica de Minas Gerais, Belo Horizonte, MG, Brasil

Resumo: Neste artigo, discutiremos as relações de poder existentes no exame que confere o Cerrificado de Proficiência em Língua Portuguesa para Estrangeiros (Celpe-Bras), o único instrumento de avaliação da proficiênncia em língua portuguesa para estrangeirios reconhecido oficialmente pelo governo brasileiro. 0 exame, que é estruturado em duas partes, escrita e oral, tem como propósito aferir o desempenho dos examinandos no uso da língua portuguesa. Considerando-se que avaliaçōes, sobretudo as de alta relevância, como é 0 caso do Celpe-Bras, são instrumentos de poder, apresentaremos, neste trabalho, reflexões a respeito de como as situaçōes de poder se dão durante as interaçōoes entre os sujeitos que participam do exame.

Palavras-chave: Exame Celpe-Bras; Prova oral; Proficiênncia linguística; Teste de desempenho; Relaçōes de poder.

Abstract: In this article, we will discuss the power relations between the exam that determines Portuguese Language Proficiency for Foreigners (Celpe-Bras), which is the only proficiency exam recognized by the Brazilian government. This exam is structured in two parts: written and oral assessments, which indicate the performance of those being examined concerning the use of the language. Considering that these evaluations, regarding the aforementioned exam are instruments of power, our main aim is to analyze how situations of power are established during the exam between examiners and examinees.

Keywords: Celpe-Bras exam; Oral test; Language Proficiency; Performance Test; Power Relations.

* Professora doutora do Centro Federal de Educação Tecnológica de Minas Gerais - CEFET -MG, Belo Horizonte, MG, Brasil; anapoles@uol.com.br

** Doutoranda pelo Programa de Estudos de Linguagens do Centro Federal de Educação Tecnológica de Minas Gerais - CEFET-MG, Belo Horizonte, MG, Brasil; liliane.olineves@gmail.com ${ }^{* * *}$ Mestre do Centro Federal de Educação Tecnológica de Minas Gerais - CEFET-MG, Belo Horizonte, MG, Brasil; nataliatosatti@yahoo.com.br 
Linha D'Água (Online), São Paulo, v. 30, n. 1, p. 115-126, jun. 2017

\section{Considerações iniciais}

No campo dos estudos linguísticos, é crescente o número de pesquisas que têm como foco os exames de proficiência, em que são discutidos aspectos atinentes à validade, à confiabilidade, ao efeito retroativo, aos aspectos linguístico-discursivos, gramaticais, entre outros.

A partir de uma perspectiva social, pode-se afirmar que esses exames são considerados um objeto de poder, pois são o instrumento utilizado para atestar determinados saberes de um indivíduo e, consequentemente, para selecioná-lo ou excluí-lo de determinadas esferas.

No contexto brasileiro, o exame que confere Certificado de Proficiência em Língua Portuguesa para Estrangeiros, doravante Celpe-Bras, é o único instrumento de avaliação da proficiência em língua portuguesa para estrangeiros reconhecido oficialmente pelo governo. Nesse sentido, buscamos discutir as relações de poder no Celpe-Bras, focalizando a prova oral do exame.

Aplicado desde 1998, os números relativos ao crescimento e à expansão do Celpe-Bras revelam-no como um exame de grande relevância quando se fala em instrumento de avaliação. Desenvolvido e outorgado pelo Ministério da Educação do Brasil, é aplicado, tanto no Brasil como no exterior com o apoio do Ministério das Relações Exteriores, e é exigido por instituições de ensino, entidades de classe e empresas como a comprovação de competência do examinando na língua portuguesa.

Embora seja relativamente novo, o Celpe-Bras pode ser considerado um exame de proficiência de alta relevância, na medida em que o número de interessados aumenta cada vez mais e o seu uso se institucionaliza.

De natureza comunicativa, o Celpe-Bras propõe-se a avaliar o desempenho de examinandos a partir de duas provas. Uma, escrita, composta por quatro tarefas que envolvem a compreensão de vídeo, áudio, textos escritos e a produção de textos escritos; a outra, oral, em que há a presença de dois avaliadores, um observador e um entrevistador, sendo que este último interage com o examinando, face a face, a partir das informações constantes da sua ficha de inscrição e a partir de alguns 
Linha D'Água (Online), São Paulo, v. 30, n. 1, p. 115-126, jun. 2017

elementos provocadores ${ }^{1}$ que tratam de assuntos do cotidiano. Tanto o entrevistador quanto o observador têm seu papel na avaliação do examinando. Enquanto o primeiro tem como referência uma grade holística, o segundo pauta-se numa avaliação analítica.

Para obter o certificado, o examinando deve alcançar desempenho satisfatório nas duas provas, sendo que os níveis de proficiência avaliados são: básico (sem certificação), intermediário, intermediário superior, avançado e avançado superior.

No que se refere à prova oral do Celpe-Bras, foco deste artigo,

espera-se que o examinando tenha capacidade de conversar, da forma mais natural possível, sobre assuntos do cotidiano e da atualidade veiculados na mídia brasileira. Vale salientar que não se trata de uma entrevista na qual uma pessoa pergunta e a outra responde de forma mecânica, mas sim de uma simulação de conversa em língua portuguesa (BRASIL, 2013a, p. 28).

A interação face a face é dividida em dois momentos significativos: nos primeiros cinco minutos da interação, o examinando deve demonstrar capacidade de conversar sobre questões de natureza pessoal. Nessa etapa, a chamada "quebragelo", espera-se criar um ambiente favorável para a interação, de tal forma que o examinando se sinta mais à vontade para revelar a sua capacidade de comunicação, exprimindo entendimento sobre os temas tratados. No segundo momento, o examinando tem acesso a três elementos provocadores, um por vez, cujos temas são discutidos entre ele e o entrevistador, a partir de um roteiro de perguntas previamente elaborado. Para cada elemento provocador, são reservados cinco minutos para a sua leitura e para a interlocução.

É na prova oral que o examinando participa de uma interlocução cujo contrato de comunicação ${ }^{2}$, nos termos da Teoria Semiolinguística, é bem definido, ou

1 Os elementos provocadores contêm textos verbais e não verbais e são utilizados para desencadear a conversa entre examinando e entrevistador e são escolhidos pelo entrevistador a partir das informações constantes da ficha de inscrição do examinando.

2 Contrato de comunicação é o conjunto das condições nas quais se realiza qualquer ato de comunicação (qualquer que seja sua forma, oral ou escrita, monolocutiva ou interlocutiva). É o que permite aos parceiros de uma troca linguageira reconhecerem um ao outro com os traços identitários que os definem como sujeitos desse ato (identidade), reconhecerem o objetivo do 
Linha D'Água (Online), São Paulo, v. 30, n. 1, p. 115-126, jun. 2017

seja, o examinando aceita as condições de aplicação do exame, submetendo-se a uma entrevista, primeiro momento da prova, e a uma conversa sobre tópicos do cotidiano, que caracteriza o segundo momento da prova. É a partir desse contrato preestabelecido que o entrevistador propõe perguntas e diálogos e o examinando demonstra aquilo que entendeu do tema, o que sabe sobre a cultura brasileira, sobre a sua própria cultura e, desse modo, revela o seu nível de proficiência oral. Trata-se, portanto, de uma situação de comunicação em que os sujeitos envolvidos, a partir da aceitação tácita do contrato, agem visando a um mesmo objetivo: a avaliação do desempenho linguístico.

\section{O ethos e as relações de poder}

Nessa situação interativa, em que os papéis linguageiros são bem definidos, tanto entrevistador quanto examinando constroem uma imagem um do outro, no e pelo discurso, que carrega marcas do enunciador. No que toca a essa construção de imagem, Barthes (apud Maingueneau, 2005, p. 70) define o ethos como "os traços de caráter que o orador deve mostrar ao auditório (pouco importando sua sinceridade) para causar boa impressão: são os ares que assume ao se apresentar (...). O orador enuncia uma informação e ao mesmo tempo diz: eu sou isso e não aquilo". Pode-se dizer que esses traços de caráter são revelados pelas escolhas linguísticas de que o enunciador lança mão para organizar o seu discurso, ou seja, essas escolhas revelam pistas do ethos do enunciador.

Todo discurso, oral ou escrito, supõe um ethos: implica uma certa representação do corpo de seu responsável, do enunciador que se responsabiliza por ele. Sua fala participa de um comportamento global (uma maneira de se mover, de se vestir, de entrar em relação com o outro...). Atribuímos a ele, dessa forma, um caráter, um conjunto de traços psicológicos (jovial, severo, simpático...) e uma corporalidade (um conjunto de traços físicos e indumentários). 'Caráter' e 'corporalidade' são inseparáveis, apoiam-se em estereótipos valorizados ou desvalorizados na

ato que os sobredetermina (finalidade), entenderem-se sobre o que constitui o objeto temático da troca (propósito) e considerarem a relevância das coerções materiais que determinam esse ato (circunstâncias) (CHARAUDEAU e MAINGUENEAU, 2008, p. 132). 
Linha D'Água (Online), São Paulo, v. 30, n. 1, p. 115-126, jun. 2017

coletividade, em que se produz a enunciação (MAINGUENEAU, 2006, p. 60 grifos no original).

Em se tratando da prova oral do Celpe-Bras, é possível afirmar que os sujeitos entrevistador e examinando constroem um ethos pré-discursivo (a imagem que o coenunciador constrói do enunciador antes mesmo que este pronuncie algo), imagem esta que pode ser confirmada ou não durante a interlocução, a partir da percepção do caráter e da corporalidade de que trata Maingueneau (2006).

Considerando-se que, para muitos examinandos, o momento da interação pode ser um momento de tensão, pois trata-se da sua avaliação, os cinco minutos iniciais da prova, o "quebra-gelo", podem ser determinantes para a quebra de uma possível imagem negativa do entrevistador. Isso porque é nesse momento que o entrevistador deve tentar deixar o examinando mais à vontade, para que este possa demonstrar melhor o seu desempenho linguístico.

Tendo em vista que são as relações discursivas que norteiam toda a prova oral do exame Celpe-Bras, adotamos a definição foucaultiana de "discurso", para sustentar as nossas discussões a respeito do poder que envolve esse instrumento de avaliação. De acordo com o Dicionário Foucault,

(...) o discurso geralmente designa, na obra de Foucault, um conjunto de enunciados que podem pertencer a campos diferentes, mas que obedecem, apesar de tudo, a regras de funcionamento comuns. Essas regras não são apenas linguísticas ou formais, mas reproduzem uma série de divisões historicamente determinadas (por exemplo, a grande divisão razão/desrazão): a "ordem do discurso" própria de um período particular possui, portanto, uma função normativa e reguladora e estabelece mecanismos de organização do real por meio da produção de saberes, de estratégias e de práticas (REVEL, 2011, p. 41).

Para Foucault, o discurso é, também, um jogo. 
Linha D'Água (Online), São Paulo, v. 30, n. 1, p. 115-126, jun. 2017

O discurso nada mais é do que a reverberação de uma verdade nascendo diante de seus próprios olhos (...). Quer seja, portanto, em uma filosofia do sujeito fundante, quer em uma filosofia da experiência originária ou em uma filosofia da mediação universal, o discurso nada mais é do que um jogo, de escritura, no primeiro caso, de leitura, no segundo, de troca, no terceiro, e essa troca, essa leitura e essa escritura jamais põem em jogo senão os signos. O discurso se anula, assim, em sua realidade, inscrevendo-se na ordem do significante (FOUCAULT, 2005, p. 49).

Segundo o filósofo, "a produção do discurso é, ao mesmo tempo, controlada, selecionada, organizada e redistribuída por certo número de procedimentos que têm por função conjurar seus poderes e perigos, dominar seu acontecimento aleatório, esquivar sua pesada e temível materialidade" (FOUCAULT, 2005, p. 8-9).

Para controlar os agentes do discurso, há procedimentos de exclusão, interdição. Sabe-se bem que não se tem o direito de dizer tudo, que não se pode falar de tudo em qualquer circunstância, que qualquer um, enfim, não pode falar de qualquer coisa (FOUCAULT, 2005, p. 9). Para esse autor, o discurso é, nesse contexto de práticas sociais, considerado um objeto de desejo, é o poder que se quer obter.

No cenário da prova oral do Celpe-Bras, a produção de discurso também é controlada e nela estabelecem-se relações de poder, relações essas que podem ser identificadas tanto externamente ao ato de comunicação (na interação face a face), quanto internamente. Externamente, pode-se afirmar que há diversas esferas em que essas relações são estabelecidas, como, por exemplo, entre o Estado brasileiro e/ou instituições que exigem o exame e os indivíduos que precisam comprovar sua proficiência linguística; entre o Instituto Nacional de Estudos e Pesquisas Educacionais Anísio Teixeira (Inep - órgão que administra o exame) e os postos aplicadores; entre os postos aplicadores e os colaboradores que aplicam o exame. Cada uma dessas instâncias detém determinados tipos de saber, que entram em jogo no momento em que se apoderam do discurso para realizar alguma ação.

Internamente ao ato de comunicação, as relações de poder são estabelecidas entre o entrevistador e o examinando, sendo que o primeiro é responsável por manter e regular o fluxo da conversa, por meio de informações contidas na ficha de inscrição do examinando e dos elementos provocadores. Nessa relação interna, 
Linha D'Água (Online), São Paulo, v. 30, n. 1, p. 115-126, jun. 2017

há um fator externo que também interfere no ato de comunicação: as normas que regem a aplicação, às quais o entrevistador deve obedecer para a garantia da validade e confiabilidade do exame. Essas normas são, portanto, as que controlam a produção de discurso que configura a prova oral, ou seja, o entrevistador não pode dizer o que quer, da forma que quer, pois o seu discurso é controlado.

Se, por um lado, o entrevistador é um sujeito legitimado para conduzir a entrevista e avaliar o desempenho do examinando, exercendo certo poder (assim como o observador), por outro, é necessário que o construto que subjaz ao exame seja refletido nessas duas ações, conforme afirma Furtoso (2011):

(...) a intervenção do avaliador, conhecedor das concepções que fundamentam o Exame, é de suma importância para assegurar que todo o processo, desde o (re) conhecimento do perfil do examinando até a avaliação de sua proficiência, seja realmente um espaço de negociação de significados e de busca pela cooperação entre línguas-culturas diferentes, contemplando, assim, quem fala, de onde, com quem e para quem. $O$ entrevistador, nesse sentido, é o que assume a voz das concepções que fundamentam o Exame, enxergando e ouvindo o outro para que a interação faça sentido e os conflitos culturais sejam minimizados (FURTOSO, 2011, p. 234 - grifo nosso).

Como se pode perceber, o papel que os avaliadores (entrevistador e observador) exercem é, de fato, de suma importância e a conduta deles pode interferir, positiva ou negativamente, no desempenho do examinando. Dada essa preocupação, como Furtoso (2011) aponta, as habilidades desses sujeitos também são objeto de documentos normativos, a exemplo da Portaria no $334^{3}$, Anexo I, item II.

Art.5 Os examinadores da Parte Oral devem possuir as habilidades necessárias para conduzir o processo de aplicação das provas, conhecer o construto teórico do Exame, saber planejar e conduzir as interações, manejar os equipamentos utilizados, conhecer a grade de avaliação, compreender bem as delimitações de níveis

3 A referida Portaria dispõe sobre o credenciamento, recredenciamento e descredenciamento de Postos Aplicadores e define procedimentos para aplicação do exame Celpe-Bras. Foi exarada pelo presidente do INEP à época, o Sr. Luiz Cláudio Costa, e publicada no Diário Oficial da União, em 4/7/13, seção 1, páginas 16 a 17. 
Linha D'Água (Online), São Paulo, v. 30, n. 1, p. 115-126, jun. 2017

do Celpe-Bras e agir com cordialidade, lembrando-se de que estão em situação formal de interação (BRASIL, 2013b, p. 17).

Nesse ato de comunicação que caracteriza a interação face a face, as relações de poder, externas e internas, são estabelecidas no e pelo discurso, portanto cabe aos sujeitos envolvidos assumirem o papel linguageiro que lhes foi destinado, considerando-se, sempre, o construto teórico do exame.

\section{Considerações finais}

Ao tratar da validade de testes, Bachman (1990, p. 279) afirma que esses instrumentos "não são desenvolvidos e usados em um tubo psicométrico livre de valores, eles são quase sempre elaborados a fim de atender às necessidades de um sistema educacional ou da sociedade em geral". Fazendo reflexões sobre isso, Bachman e Palmer (1996, p. 30) consideraram que, sempre que usamos os testes, nós o fazemos em um contexto de valores e objetivos específicos e a nossa escolha trará consequências específicas ou impactos tanto para os indivíduos quanto para os sistemas envolvidos.

Numa visão crítica dos testes de língua, o ato de testar não é neutro. "Ao contrário, é, ao mesmo tempo, um produto e um agente de agendas culturais, sociais, políticas, educacionais e ideológicas que moldam a vida dos indivíduos participantes, professores e alunos" (SHOHAMY, 1998, p. 332). Essa visão entende o examinando como um sujeito político em um contexto político.

Para Madaus (1991), testes representam uma tecnologia social profundamente enraizada na educação, no governo e nos negócios; como tal, eles fornecem o mecanismo para impor poder e controle.

Testes são mais poderosos quando são muitas vezes os indicadores individuais para determinar o futuro dos sujeitos. Como critérios de aceitação e rejeição, eles dominam outros dispositivos educacionais, como currículo, livro e ensino (SHOHAMY, 1998, p. 331). 
Considerando-se que os testes podem ser esses "indicadores individuais para determinar o futuro dos sujeito" e, em se tratando do exame Celpe-Bras, esse poder do teste materializa-se no momento em que, por exemplo, os médicos estrangeiros necessitam de ser aprovados, em nível mínimo de intermediário superior (nota 3, numa escala de 0 a 5), para conseguirem cumprir um dos requisitos para a revalidação do seu diploma no Brasil e, consequentemente, tornarem-se autorizados a atuar no nosso mercado de trabalho.

Essa materialização de poder evidencia-se também no fato de os estrangeiros necessitarem de certificação no exame para ingressarem em cursos de graduação ou pós-graduação no Brasil via os Programas Estudante-Convênio Graduação (PEC-G) e Pós-Graduação (PEC-PG).

Trata-se, portanto, de um exame internacional que age socialmente como uma espécie de dispositivo, em termos foucaultianos.

O termo "dispositivo" surge em Foucault na década de 1970 e designa inicialmente operadores materiais do poder, isto é, técnicas, estratégias e formas de assujeitar desenvolvidas pelo poder. A partir do momento em que a análise foucaultiana se concentra na questão do poder, o filósofo insiste na importância de não tratar "do edifício jurídico da soberania, em torno dos aparelhos do Estado, em torno das ideologias que o acompanham", mas dos mecanismos de dominação: é essa escolha metodológica que engendra a utilização da noção de “dispositivos”. Eles são, por definição, de natureza heterogênea: trata-se tanto de discursos quanto de práticas, tanto de instituições quanto de táticas instáveis: é assim que Foucault conseguirá falar, de acordo com o caso, de "dispositivos de poder", de "dispositivos de saber", de "dispositivos disciplinares", de "dispositivos de sexualidade" etc. (REVEL, 2011, p. 43).

A partir dessa definição, é possível afirmar que o exame exerce relações de poder a partir dos discursos que o fundamentam, das suas práticas sociais (aplicações) e das instituições que o representam. Trata-se, então, de um dispositivo que, segundo Agamben, numa visão ampliada da definição dada por Foucault, "é qualquer coisa que tenha de algum modo a capacidade de capturar, orientar, determinar, interceptar, modelar, controlar e assegurar os gestos, as condutas, as opiniões e os discursos dos seres viventes" (AGAMBEN, 2009, p. 12). 
Nesse contexto, o dispositivo Celpe-Bras é capaz de realizar todas essas ações, a partir do uso de um discurso que reflete o seu poder. E, diante das relações que são estabelecidas, externa ou internamente ao ato de comunicação, conforme apresentado anteriormente, podem surgir impactos ou efeitos retroativos, como, por exemplo, o aumento do número de cursos de capacitação de professores de PLE, de cursos preparatórios para o exame, de pesquisas científicas na área, entre outros, o que interfere diretamente na vida de professores, alunos e pesquisadores.

De acordo com Bachman e Palmer (1996), o impacto é uma das qualidades de testes e opera em dois níveis, quais sejam: o macro, que representa o efeito na sociedade e nos sistemas educacionais, e o micro, que representa o efeito nos indivíduos examinandos. $\mathrm{O}$ impacto também contempla uma outra característica: o efeito retroativo, que tem despertado grande interesse de pesquisadores da área da avaliação.

Em resumo, o impacto do uso de teste precisa ser considerado dentro dos valores e objetivos da sociedade e do programa educacional em que ele ocorre e de acordo com as potenciais consequências de tal uso. Ao avaliar o impacto do uso de teste, devemos considerar as características específicas do teste (finalidade, domínio da língua estrangeira, os examinandos, definição de construto) em termos de valor e objetivos dos indivíduos e do sistema educacional e da sociedade, e das potenciais consequências para os indivíduos, o sistema educacional e sociedade. A noção de efeito retroativo em testes de língua pode ser caracterizada em termos de impacto e inclui o impacto potencial sobre os examinandos e suas características, em atividades de ensino e aprendizagem, e sobre os sistemas educacionais e da sociedade (BACHMAN E PALMER, 1996, p. 35 - grifo nosso).

No Brasil, alguns pesquisadores têm se dedicado a discutir sobre esses temas, a exemplo de Scaramucci (2000/2001; 2004; 2008) e Silva (2007), o que revela serem abordagens de suma importância para a área da avaliação.

Nesse cenário de avaliação, é visível, portanto, que os interesses em um certo controle da proficiência linguística fazem com que instrumentos sejam criados, testados, analisados e aplicados cada vez mais nesse mundo globalizado e intercultural. E é nesse sentido que as pesquisas científicas tentam abarcar diversos focos de análise, a exemplo dos pressupostos teóricos que os subjazem, da forma de 
Linha D'Água (Online), São Paulo, v. 30, n. 1, p. 115-126, jun. 2017

aplicação, da capacitação e atuação de avaliadores, do desempenho dos candidatos, da validade, da confiabilidade e dos critérios de avaliação.

\section{Referências}

AGAMBEN, G. O que é um dispositivo? In: O que é contemporâneo? e outros ensaios. Tradução de Vinícius Nicastro Honesko. Chapecó, SC: Argos, 2009, 92 p.

BACHMAN, L. F. Fundamental considerations in language testing. New York: Oxford University Press, 1990, $408 \mathrm{p}$.

BACHMAN, L. F.; PALMER, A. S. Language testing in practice. New York: Oxford University Press, 1996, $377 \mathrm{p}$.

BRASIL. Ministério da Educação. Instituto Nacional de Estudos e Pesquisas Educacionais Anísio Teixeira. Guia do participante. Brasília-DF, 2013a. Disponível em http://download.inep. gov.br/outras_acoes/celpe_bras/estrutura_exame/2014/guia_participante_celpebras_caderno_ provas_comentadas.pdf Acesso em: 03 nov. 2014.

BRASIL. Ministério da Educação. Instituto Nacional de Estudos e Pesquisas Educacionais Anísio Teixeira. Portaria n. 334, de 2 de julho de 2013. Dispõe sobre o credenciamento, recredenciamento e descredenciamento de Postos Aplicadores e define procedimentos para aplicação do Exame para obtenção do Certificado de Proficiência em Língua Portuguesa para Estrangeiros (Celpe-Bras). Diário Oficial da União, Poder Executivo, Brasília, DF, 2013b. Seção 1. p. 16-17. Disponível em: <http://pesquisa.in.gov.br/imprensa/jsp/visualiza/index.jsp?data=04/07/2013\&jornal=1\&pagina=16\&totalArquivos=104> . Acesso em: 13 out. 2016.

CharaUdeaU, P.; MAINGUENEAU, D. Dicionário de Análise do Discurso. São Paulo: Contexto, 2008. 555 p.

FOUCAULT, M. A ordem do discurso: aula inaugural no Collège de France, pronunciada em 2 de dezembro de 1970.12 ed. Tradução Laura F. A. Sampaio. São Paulo: Loyola, 2005, 79 p.

FURTOSO, V. A. B. Avaliação de proficiência em português para falantes de outras línguas: relação com ensino e aprendizagem. In: MENDES, Eleise (Org). Diálogos interculturais: ensino e formação em português língua estrangeira, Campinas, Pontes Editores, 2011. p. 207-236. 
Linha D'Água (Online), São Paulo, v. 30, n. 1, p. 115-126, jun. 2017

MAINGUENEAU, D. Ethos, cenografia, incorporação. In: AMOSSY, Ruth. (Org.). Imagens de si no discurso: a construção do ethos. São Paulo: Contexto, 2005.

MAINGUENEAU, D. Termos-chave da análise do discurso. Tradução de Márcio Venício Barbosa, Maria Emília Amarante Torres Lima. Belo Horizonte, Ed. UFMG, 2006.

REVEL, J. Dicionário Foucault. Rio de Janeiro: Forense Universitária, 2011, 202 p.

SCARAMUCCI, M. V. R. Propostas curriculares e exames vestibulares: potencializando o efeito retroativo benéfico no ensino de LE (Inglês). Contexturas 5, APLIESP, Ibilce, Unesp, São José do Rio Preto, SP, 2000/2001, p. 97-109.

SCARAMUCCI, M. V. R. Efeito retroativo da avaliação no ensino/aprendizagem de línguas: o estado da arte. Trabalhos em Linguistica Aplicada, Campinas, 2004, n. 43, p. 203-226.

SCARAMUCCI, M. V. R. O exame Celpe-Bras em contexto hispanofalante: percepções de professores e candidatos. In: WIEDEMANN, Lyris; SCARAMUCCI, Matilde V. R. (Orgs.) Português para falantes de espanhol: ensino e aquisição. Campinas: Pontes Editores, 2008. p. $175-190$.

SHOHAMY, E. Critical language testing and beyond. Studies in Educational Evaluation, Tel Aviv, Israel: Pergamon. 1998, vol. 24, n. 4, p. 331-345.

SILVA, R. M. R. da. O efeito retroativo do Celpe-Bras na cultura de aprender de candidatos ao exame. 2006.142 f. Dissertação de mestrado, Universidade Federal de São Carlos, São Carlos, 2007.

Recebido: 2/3/2017.

Aprovado: 3/8/2017. 